\title{
The peaceful coexistence of ethics and quantitative research.
}

DOI:

10.1007/s10551-019-04197-6

\section{Document Version}

Accepted author manuscript

Link to publication record in Manchester Research Explorer

\section{Citation for published version (APA):}

Edwards, J. (2019). The peaceful coexistence of ethics and quantitative research. Journal of Business Ethics. https://doi.org/10.1007/s10551-019-04197-6

\section{Published in:}

Journal of Business Ethics

\section{Citing this paper}

Please note that where the full-text provided on Manchester Research Explorer is the Author Accepted Manuscript or Proof version this may differ from the final Published version. If citing, it is advised that you check and use the publisher's definitive version.

\section{General rights}

Copyright and moral rights for the publications made accessible in the Research Explorer are retained by the authors and/or other copyright owners and it is a condition of accessing publications that users recognise and abide by the legal requirements associated with these rights.

\section{Takedown policy}

If you believe that this document breaches copyright please refer to the University of Manchester's Takedown Procedures [http://man.ac.uk/04Y6Bo] or contact uml.scholarlycommunications@manchester.ac.uk providing relevant details, so we can investigate your claim.

\section{OPEN ACCESS}


The Peaceful Coexistence of Ethics and Quantitative Research

\author{
Jeffrey R. Edwards \\ Kenan-Flagler Business School \\ University of North Carolina at Chapel Hill \\ Campus Box 3490 \\ Chapel Hill, NC, 27599-3490, USA \\ $+1-919-962-3144$ \\ jredwards@unc.edu
}

Conflict of Interest: The author declares that he has no conflicts of interest.

In press, Journal of Business Ethics 


\begin{abstract}
This essay concerns the extent to which quantitative research $(\mathrm{QR})$ in management and organizational studies is divorced from ethics, as alleged in a recent $J B E$ editorial by Zyphur and Pierides (2017). After carefully examining the criticisms set forth by Zyphur and Pierides and the merits of the alternative they propose, I conclude that the problems with $\mathrm{QR}$ and the researchers who conduct it are arguably much less extreme that Zyphur and Pierides claim. This conclusion is informed by a sampling of QR studies recently published in management journals, which could be further corroborated by a more thorough review and evaluation of QR studies using principles drawn from the ethics literature. I believe this assessment would indicate that, despite room for improvement, QR and ethics can and do peacefully coexist, and quantitative researchers are largely aware of the problems and opportunities associated with integrating their work with ethics.
\end{abstract}


"Destiny guides our fortunes more favorably than we could have expected. Look there, Sancho Panza, my friend, and see those thirty or so wild giants, with whom I intend to do battle and kill each and all of them [...]."

“What giants?” asked Sancho Panza.

"The ones you can see over there," answered his master, "with the huge arms, some of which are very nearly two leagues long."

"Now look, your grace," said Sancho, "what you see over there aren't giants, but windmills, and what seems to be arms are just their sails that go around in the wind and turn the millstone." “Obviously,” replied Don Quixote, “you don't know much about adventures.”

- Miguel de Cervantes Saavedra, Don Quixote

\section{Introduction}

In management and organizational research, most empirical studies rely on quantitative research $(\mathrm{QR})$. QR can be defined as a mode of inquiry in which observations are translated into numerical quantities which are subjected to various forms of statistical analysis, ranging from descriptions of raw data to multivariate techniques such as multiple regression, factor analysis, and structural equation modeling. Results of such analyses are typically used to draw inferences about important aspects of some population of interest, such as parameters that represent relationships among theoretical constructs or effect sizes of empirical and practical importance.

QR regularly comes under scrutiny, as well it should. Statistical methods have steadily increased in sophistication, as evidenced by advancements from simple t-tests and correlations to the analysis of variance, multiple regression, path analysis, and structural equation modeling and multilevel analyses. Estimation techniques associated with these methods have likewise been improved to address violations of underlying assumptions and better accommodate the variety of data encountered by researchers. These developments have been documented in journals devoted to research methodology, such as Organizational Research Methods, Psychological Methods, Multivariate Behavioral Research, and Sociological Methods and Research, as well as handbooks and edited volumes that regularly appear in the literature. 
The occasion of this article is a critique of QR by Zyphur and Pierides (2017). These authors lamented the current state of QR, characterizing it as dry, sterile, repetitive, and unduly preoccupied with representation and correspondence. To rectify these shortcomings, the authors proposed what they termed a "monumental shift" (p. 14) in which QR is conducted "in relation to matters of serious concern, including inequality, global warming, corruption, and the like." Their recommendations implore quantitative researchers to reject ready-made formulas, rules of thumb, and universal "best practices" for conducting and evaluating QR, move beyond research that pursues representation and correspondence, and adopt what the authors describe as a "built for purpose" approach that emphasizes "orientations" and "ways of doing" research.

The allegations leveled by Zyphur and Pierides are stated in forceful terms that admonish the practice of QR and the researchers who conduct it. Such allegations should not be taken lightly, and the recommendations set forth by the authors are worthy of consideration. In some ways, these recommendations are useful, if not familiar, as they echo recurring discussions of the tensions between rigor and relevance in management research and urge quantitative researchers to reflexively examine how they pursue their work. However, Zyphur and Pierides present little evidence to substantiate the prevalence and severity of the problems they describe. Moreover, the "built for purpose" alternative they propose, with its rejection of established methodological standards, risks setting the stage for a methodological free-for-all in which researchers choose whatever criteria they deem worthy to justify how they conduct their work.

Fortunately, digging deeper into the issues raised by Zyphur and Pierides reveals that QR is not as disconnected from worldly concerns as the authors allege. Moreover, QR methodology, with its emphasis on representation and correspondence, does not place restrictions on the types of questions researchers can pursue, and studies that utilize QR frequently focus on worldly problems that are relevant to individuals, organizations, and society at large. And fortunately, I think most readers would agree that quantitative researchers are not a hapless band of misguided souls who mindlessly adhere to methodological rituals and disregard the relevance and import of the questions they pursue, as Zyphur and Pierides would have us believe. In what follows, I 
address the criticisms of QR set forth by Zyphur and Pierides, consider the merits of their proposed alternative, and offer the conclusion that ethics and $\mathrm{QR}$ are not at odds, but can and do coexist peacefully, such that the rigorous conduct of $\mathrm{QR}$ readily accommodates a wide range of research questions, including those with important ethical implications.

\section{Criticisms of the Practice and Practitioners of Quantitative Research}

Zyphur and Pierides begin by describing their view of the current status of QR. On p. 2, they state:

$\mathrm{QR}$ is often done in terms of representation and correspondence ... In this narrative, worldly phenomena are represented in research, including by theories, hypotheses, models, equations, samples, data, or parameter estimates. In turn, these can be true, valid, or unbiased by corresponding to their worldly counterparts, for example, when observed data correspond to what they are meant to measure or parameter estimates corresponding to correlations or causal effects in a population.

This statement is arguably a fair characterization of QR, and most of those who conduct it would probably take little exception to the notion that, through their research, they attempt to represent real-world phenomena and are concerned with how well these representations correspond to the phenomena of interest. However, Zyphur and Pierides argue that QR, as they characterize it, creates two problems: an ethic of probabilistic inference; and a simplistic understanding of QR. I address these two arguments in turn.

\section{Ethic of Probabilistic Inference}

Zyphur and Pierides state that quantitative researchers often describe their core purpose as producing inferences that are true, valid, and unbiased, and yet this pursuit runs headlong into a dilemma, which is that "the world can only be represented" and therefore "correspondence is always uncertain because the world can never be known 'in itself'"' (p. 3). The authors state that quantitative researchers address this uncertainty by relying on probabilistic inference, which purportedly has a crippling effect: 
this ethic of probabilistic inference cripples quantitative researchers, who may find it difficult to consider ethical issues on terms that are contextually relevant rather than in relation to a 'problem of inference' ... the problem is that focusing on representation and correspondence produces an orientation toward 'facts' rather than 'values' ... probabilistic inference tends to universalize elements of its computation with conceptual tools such as 'samples,' 'populations,' and the like, which are (erroneously) not conceived of as being constructed based on values - and therefore ethics.

These charged words are likely to attract the attention of quantitative researchers. After all, who among us would willingly adhere to methods that cripple our work and disconnect it from values and ethics?

Fortunately, this characterization of QR bears little resemblance to how it is typically practiced. For instance, the idea that correspondence is always uncertain lies at the heart of measurement and construct validation, which rely on the widely accepted premise that no measure is perfect, and therefore multiple measures should be used to tap into constructs that themselves cannot be directly observed (Campbell \& Fiske, 1959; Cronbach \& Meehl, 1955). Moreover, the uncertainty inherent in measurement is well understood, characterized as measurement error in reliability estimation (Cronbach, Gleser, Nanda, \& Rajaratnam, 1972; Nunnally, 1978) and uniqueness in factor analysis (Harman, 1976; Mulaik, 2009). Quantitative researchers do indeed grapple with this uncertainty using methods that rely on probabilistic inference, but doing so does not have the crippling effect described by Zyphur and Pierides, because the choice of these methods has no bearing on the substance of the research questions pursued, which can be "contextually relevant" as dictated by the interests of the researcher and the intended contribution of the study.

With respect to values, Zyphur and Pierides provide little evidence to substantiate their argument that quantitative researchers are unaware that the choices they make when conducting their research reflect the values they hold. Indeed, the role of values in the research process has 
been acknowledge for decades (e.g., Booth, Colomb, \& Williams, 2008; Howard, 1985; Kimmel, 1988; Mowday, 1997). Based upon their review of the organizational sciences, Connell and Nord (1996) concluded that there is widespread recognition that "interests or values have been and continue to be major factors in shaping what constitutes knowledge in the field" (p. 407). Moreover, articles that present QR often begin by describing some contextualized issue or problem that motivates the ensuing empirical work, and doing so implicates what is valued by the authors and the individuals, groups, organizations, and other constituencies related to the study. I elaborate these issues later by reviewing the orientations of QR studies as represented by a sample of recently published work.

Concerning ethics, books devoted to quantitative research methods regularly include material devoted to research ethics (e.g., Adams \& Lawrence, 2019; Brewerton \& Millward, 2001; Rogelberg, 2002; Shadish, Cook, \& Campbell, 2002; Tharenou, Donohue, \& Cooper, 2007; Weathington, Cunningham, \& Pittenger, 2010). Moreover, journals that publish QR typically provide instructions for authors that address ethical aspects of the publication process, such as ensuring that the manuscript has not been previously published or under review at another journal, maintaining the anonymity of the review process, revealing any conflicts of interest, and attesting that the treatment of study participants conforms to applicable ethical standards. Furthermore, many quantitative researchers belong to professional associations, such as the Academy of Management, the Strategic Management Society, the American Psychological Association, and the American Sociological Association have codes of ethics that members are expected to follow and standing committees responsible for promoting ethical compliance and handling violations that might arise. As such, quantitative researchers are engaged in ethical considerations throughout the design, conduct, and publication of their work.

Simplistic Understanding of Quantitative Research

Zyphur and Pierides further argue that QR narratives create a simplistic understanding of the QR process. They introduce this point as follows (pp. 3-4):

By emphasizing formal logics such as statistics and probability, researchers can 
fail to notice the actual doing of research, including the production of representations and the creation and use of specific tools for testing correspondence. In turn, by overlooking how $\mathrm{QR}$ is done, many researchers fail to see how the theory of knowledge that accompanies QR binds narratives of representation and correspondence to the assumption that this is the only reasonable way to understand abstractions such as "knowledge" or "truth" [emphasis in original].

With these remarks, Zyphur and Pierides allege that those who practice QR adhere to it with blind devotion, elevating QR above all other methods as the key to discovering what they hope to understand. Subsequent comments more directly target quantitative researchers themselves. Quoting from p. 4, where Zyphur and Pierides describe the adherents of QR:

$[\mathrm{QR}]$ researchers fail to see the rather obvious reality that they coproduce what they propose to merely represent, including populations, variables, statistical parameters, chance or probabilities, and constructs ... researchers are falsely construing themselves as being in a passive role that merely represents what existed "all along," or that is purported to exist outside of the descriptive processes that define QR.

Hence, Zyphur and Pierides assert that there is no such thing as "reality" out there waiting to be discovered - instead, quantitative researchers coproduce what they attempt to observe, and these researchers are woefully unaware of how their use of QR affects what they study and observe.

These assertions can be questioned on several grounds. First, it is well understood that the results obtained from $\mathrm{QR}$ are affected by the methods and procedures involved. These effects have been described in various terms, such as observer effects, reactivity, demand characteristics, method variance, and other types of artifacts in empirical research (Hoyt, 2000; Podsakoff, MacKenzie, \& Podsakoff, 2012; Rosenthal \& Rosnow, 2009). Moreover, quantitative researchers themselves have critically examined the effects of their own judgment calls on primary studies (McGrath, Martin, \& Kulka, 1982) and meta-analysis (Aguinis, Dalton, 
Bosco, Pierce, \& Dalton, 2011; Wanous, Sullivan, \& Malinak, 1989). Thus, it seems safe to say that most quantitative researchers are aware that their methodological choices, and the values that might underlie these choices, influence the observations and conclusions derived from $\mathrm{QR}$.

Second, although the methods used in QR arguably impact representations of reality, they do not create that reality itself, which exists independently of researchers. For instance, people experienced attitudes, held beliefs, and engaged in behavior long before social scientists arrived on the scene to study these phenomena. The same can be said for the various topics pursued in studies of dyads, teams, organizations, firms, and other social collectives commonly examined in QR. From this perspective, the phenomena researchers study exist in the real world, but these phenomena cannot be observed or understood with perfect accuracy due to the limitations of the research methods employed and the restricted capabilities of researchers themselves. Certainly, what researchers observe is filtered by the measures used and how they are applied, and the act of observing can influence what is observed, as noted earlier in reference to reactivity, observer effects, demand characteristics, and the like. Arguably, most quantitative researchers are aware of these issues, and remedies have been developed, with unobtrusive observation as a case in point (Webb, Campbell, Schwartz, \& Sechrest, 1966; Webb \& Weick, 1979). Hence, although the methods used in QR influence the resulting representations, saying that researchers "coproduce what they propose to merely represent" takes matters too far.

Third, QR does not itself pigeonhole researchers into passive roles as mere observers. To the contrary, certain types QR studies can be designed as interventions to bring some type of change to the participants under study and the situations that surround them. Perhaps the most straightforward examples are field experiments, in which one or more manipulations are introduced and their effects are observed (Shadish et al., 2002). Ideally, cases are randomly assigned to the manipulated conditions, resulting in a true experiments (Eden, 2017; Gerber \& Green, 2012), whereas when random assignment is impractical or unethical, the study would be regarded a quasi-experiment (Cook, Campbell, \& Peracchio, 1990; Grant \& Wall, 2009). Another example is action research (Greenwood \& Levin, 2007; Reason \& Bradbury, 2008; 
Stringer, 2014), which traces its roots to Lewin (1946). The essence of action research entails a partnership between scientists and practitioners that involves setting objectives, gathering information, generating solutions, taking action, and assessing the resulting effects. This process is compatible with QR methods, particularly those that involve measurement, estimating effect sizes, and assessing their statistical and practical significance. More broadly, Argyris, Putnam, \& Smith (1985) emphasized what they termed "the continuities between the activities of science and the activities of learning in the action context" and the mutually reinforcing benefits of combining science and social practice (pp. 7-8). Along similar lines, Aguinis (1993) critically compared action research and normal science and concluded that both emphasize the importance of establishing causality, the use of experimental methods, and collecting quantitative data to supplement qualitative observations. Thus, rather than limiting research to mere description, QR can play a crucial role in research that develops and implements interventions and assesses their effects. As such, QR can be arrayed on a continuum ranging from unobtrusive observation to active participation in the research context and the individuals and organizations under study.

\section{Proposed Alternative}

Following their critique of QR, Zyphur and Pierides propose an alternative framed around two dimensions labeled "orientations" and "ways of doing." An orientation is defined as "a way of realizing the purpose(s) of a study" that "helps to determine what is observed or found to exist in a research setting" (p. 5). They further state that orientations differ with respect to the audiences served, the kinds of knowledge produced, and the motivations for doing research. The meaning of ways of doing is less explicit, in that Zyphur and Pierides indicate that it involves "more than what is often implied by "quantitative methods"" (p. 7) but then discuss ways of doing in terms of research design (i.e., samples and populations, measures, causal inference), data analysis, and inductive inference, which are hallmarks of quantitative methods. As part of this discussion, Zyphur and Pierides express concerns about the use of internal and external validity as guiding principles of $\mathrm{QR}$, arguing that these notions of validity "distract from whether or not a study works to ethically achieve its purposes" (p. 7). To address these concerns, Zyphur 
and Pierides propose to "collapse and remake" internal and external validity into what they call "relational validity," which exists when "a study produces and connects relevant purposes with its orientation and ways of doing QR in an ethically informed manner" (p. 7). The balance of their discussion is devoted to applying relational validity to research design, data analysis, and inductive inference, with the primary message that decisions guiding the conduct of QR should take into account the purpose and goals of the research, the surrounding context, and the ethical issues underlying how studies are conducted and the questions they pursue.

I suspect most quantitative researchers would agree that methodological choices should not be made in ritualistic ways that disregard the goals, context, and ethical implications of their research. These ideas are not particularly controversial and, for the most part, seem to describe $\mathrm{QR}$ as it is currently practiced. To investigate the extent to which current $\mathrm{QR}$ is aligned with the prescriptions of Zyphur and Pierides, I reviewed articles published in the first issues of 2018 that appeared in the Academy of Management Journal, Administrative Science Quarterly, the Journal of Applied Psychology, Organizational Behavior and Human Decision Process, and the Strategic Management Journal. These journals span most of the core topics in management research and consistently appear in the upper echelons of journal rankings (McWilliams, Siegel, \& Van Fleet, 2005). The number of articles in these journals that presented QR was $14,3,8,13$, and 8 , respectively, yielding 46 articles in all. The authors and titles of the articles are presented in Table 1.

A perusal of these articles indicates that the vast majority examined topics that speak to issues of importance to individuals, teams, organizations, and society. At the individual level, topics include balancing the demands of work and family (Bhave \& Lefter, $A M J$ ), how tensions created by resource scarcity relate to job performance (Miron-Spektor et al., AMJ), how informal learning enhances job performance in units with supportive climates (Wolfson et al., JAP), biases in perceptions of risk (Schlosser, $O B H D P$ ), how employees' perceived control over their performance is impacted by the overall health of the economy (Sirola \& Pitesa, OBHDP), why employees believe they have less control over more important events (Tang et al., $O B H D P$ ), how 
people respond when their social identity is threatened (White et al., $O B H D P$ ), the effects of trash-talking on incivility, rivalry, and unethical behavior (Yip et al., $O B H D P$ ), and the effects of experience, training, and resources on pursuing entrepreneurial careers (Lyons \& Zhang, SMJ),

At the team level, the studies addressed how team mindfulness relates to conflict and social undermining ( $\mathrm{Yu} \&$ Zellmer-Bruhn, $A M J$ ), how leaders encourage team members to express ideas and concerns (Farh \& Chen, $J A P$ ), how changes initiated by work units can simulate organizational change (Wee et al., JAP), status conflict and team creativity (Lee et al., $O B H D P$ ), and team communication and performance (Marlow et al., $O B H D P$ ). Looking more narrowly at the dyadic level, topics include the authenticity of emotions displayed in customer service encounters (Cheshin et al., OBHDP; Houston et al., OBHDP), how self-disclosure undermines perceived status (Gibson et al., $O B H D P$ ), illusions of transparency when providing negative feedback (Schaerer et al., $O B H D P$ ), and the effects of gender on the relationship between board chairs and CEOs (Oliver et al., SMJ).

At the organization level, we learn how organizations collaborate with customer and community stakeholders (Desai, $A M J$ ), develop radical technologies (Eggers \& Kaul, $A M J$ ), foster inventions that result in patents (Giarratana et al., $A M J$ ), leverage selection practices to promote firm performance (Kim \& Ployhart, $A M J$ ), and set an affective tone that eases strain among employees (Knight et al., $A M J$ ). The studies also addressed the selection of partners in strategic alliances (Zhelyazkov, $A S Q$ ), the formation of alliance networks in the biotechnology industry (Jiang et al., $S M J$ ), and the relationship between divestitures and subsequent firm performance (Vidal \& Mitchell, $S M J$ ). Some of these studies examined topics that involve tension and conflict, such as how companies manage perceptions of hypocrisy (Carlos \& Lewis, $A S Q$ ), desire but often reject creative ideas (Mueller et al., $A M J$ ), deal with distrust following organizational misconduct (Yenkey, $A S Q$ ), and respond to economic and political stakeholders when managing innovation (Li et al., SMJ),

Beyond these practical issues, some of the studies reviewed addressed topics with clear ethical implications. At the individual and interpersonal levels, examples include unethical 
behavior arising from incivility and rivalry (Yip et al., $O B H D P$ ), cheating behavior resulting from pressure to perform (Mitchell et al., JAP), racial bias in customer service (Houston et al., $O B H D P$ ), pride and anger pertaining to the social context of negotiations (Becker et al., JAP), and proactive behavior intended to help others (Wu et al., $A M J)$. At the firm and institutional levels, studies addressed the effects of organizational scandals (Piazza \& Jourdan, $A M J$ ), resilience in the face of disasters (Rao \& Greve, $A M J$ ), corporate social responsibility (Ong et al., $O B H D P$ ), the public's opinion of fair compensation for victims of emotional losses (Zhang et al., $O B H D P$ ), fraud and corruption in the stock brokerage industry (Yenkey, $A S Q$ ), and sexism in the corporate boardroom (Oliver et al., SMJ). Finally, a handful of articles adopt a reflective stance on the conduct of QR itself, examining statistical methods for assessing the effects of interventions in organizations (Bodner et al., $J A P$ ), the shift from basic to commercial research in U.S. firms (Arora et al., SMJ), and the use of text matching to measure the technological similarity of patents (Arts et al., SMJ).

Although this sample of articles is admittedly limited, I believe it provides a reasonably representative profile of $\mathrm{QR}$ studies currently published in management journals. If we accept this premise, then it seems safe to say that most quantitative researchers already recognize the importance of connecting their work to what Zyphur and Pierides call orientations, and decisions that guide the various ways of doing this research take into account what the studies are intended to accomplish. As such, it is reasonable to question whether following the advice of Zyphur and Pierides would require "a monumental shift in what many QR practitioners care about" such that, "Instead of merely attempting to produce representations that correspond more or less well - as if the goal of research was to setup and manage a xerox copying facility - QR must be done in relation to matters of serious concern" (p. 14). To the contrary, quantitative researchers regularly connect their work to concerns that are relevant to individuals, groups, organizations, and society, and there is little evidence that such concerns are subordinated to methodological principles that promote internal and external validity and inform sampling, measurement, data analysis, and causal and inductive inferences. In short, although Zyphur and Pierides provide 
recommendations that are generally sound, they present an unfair characterization of current QR and the many researchers who strive to practice it in ways that are diligent, conscientious, and intended to address important problems.

\section{Whither Ethics?}

Throughout their article, Zyphur and Pierides argue that QR as it is typically practiced is disconnected from ethics. They encapsulate this argument as follows (p. 1):

Our central claim is that ready-made formulas for $\mathrm{QR}$, including 'best practices' and common notions of 'validity' or 'objectivity,' are often divorced from the ethical and practical implications of doing, evaluating, and using QR for specific purposes.

Conspicuously missing from this discussion is a definition of ethics and a corresponding set of criteria by which the ethics of QR can be evaluated. Indeed, scouring the Zyphur and Pierides article reveals only a handful of instances in which the meaning of ethics is addressed. One such instance is the discussion of probabilistic inference, which the authors characterize as "the dominant ethic of QR practice, in which researchers ought to generate representations with the highest probability of correspondence" (p. 3, emphasis in original). Elsewhere, the authors associate ethics with values, as evidenced by statements such as "probabilistic inference tends to universalize elements of its computation with conceptual tools such as 'samples,' 'populations,' and the like, which are (erroneously) not conceived of as being constructed based on values and therefore ethics" (p. 3), and "A focus on valid inferences leads to abstractions that are distant from the values and ethics that a study embodies ... By separating facts from values, facts appear to be unrelated to ethics; and with a focus on facts, ethics appear irrelevant for QR validity" (p. 7). Beyond these instances, the intended meaning of ethics remains elusive.

The evaluation of QR in ethical terms would be greatly enhanced by drawing from the many theories and frameworks available in the ethics literature. Although this literature is vast, useful summaries can be found in integrative discussions of business ethics (e.g., Beauchamp \& Bowie, 1997; Brady, 1985; Donaldson, 1982; Treviño \& Nelson, 2011; Velasquez, 2012). These 
discussions outline various approaches than can be used to evaluate the ethics of QR. One approach frames ethics in terms of consequences, such that an action or decision is deemed ethical when it produces the maximum benefit and minimum harm for the affected parties. This approach is represented by classic discussions of utilitarianism by Bentham (1789/1961) and Mill (1861/1998). From this perspective, the ethics QR would evaluated in terms of its consequences for constituencies such as study participants, the individuals and organizations whose needs and concerns motivate the research, agencies who provide support for research, and the researchers themselves. Another approach is represented by deontology, which involves the extent to which actions themselves are consistent with prevailing rules and norms regarding what is morally right. With this approach, the ethics of QR would be evaluated by how it is conducted, using criteria that might include honesty, integrity, impartiality, altruism, and respect with regard to the parties involved in the research process. A third approach draws from virtue ethics, which is rooted in philosophical discussions by Plato and Aristotle that address the character of moral actors. This approach would direct our attention to quantitative researchers themselves and the extent to which they develop and display ethical and moral virtues for their own sake.

The application of criteria such as these to the evaluation of QR should be preceded by constructing a representative sample of studies drawn from the relevant literature. This could be accomplished by identifying journals that publish QR, designating a time frame to be covered, and establishing selection criteria to determine which studies should be included or excluded. Once the sample of studies has been constructed, raters could apply some method of scoring to assess the ethics of the individual studies, and the agreement among these ratings could be examined. Finally, the ratings could be summarized to indicate the extent to which the research reviewed satisfy criteria for ethical QR, supplemented by analyses that examine differences across types of studies, trends over time, and other dimensions of interest. This approach would provide a more defensible assessment of the ethics of QR than the sweeping generalizations offered by Zyphur and Pierides, which would likely be difficult to replicate through independent 
reviews of the literature.

\section{The Status of Research Published in the Journal of Business Ethics}

Finally, it should be noted that the Zyphur and Pierides article is framed as an editorial that, among other things, is intended to influence submissions to $J B E$. This framing is illustrated by the following passage (p. 7).

some researchers may still feel that we are unclear regarding what an orientation is and how to adopt one. This feeling of uncertainty is expected from researchers who appreciate ready-made $\mathrm{QR}$ formulas, in place of having to consider the ethics of QR. As in life generally, there are no easy answers for how researchers should be oriented, but for $J B E$ an overriding concern should be the ethical implications of orientations that drive the production of QR. Whose purposes are served by an orientation? In what ways is an orientation useful for addressing matters of worldly concern? There are no singularly right ways to understand or deploy orientations, but these are the kinds of questions that may be asked and answered in papers submitted to $J B E$.

This passage, and others that describe how authors should orient their submissions for $J B E$, raises the question of whether the recommendations of Zyphur and Pierides differ from how $J B E$ is currently positioned. This does not seem to be the case, as indicated by the description of the Aims and Scope section of the $J B E$ website:

The Journal of Business Ethics publishes only original articles from a wide variety of methodological and disciplinary perspectives concerning ethical issues related to business that bring something new or unique to the discourse in their field. Since its initiation in 1980, the editors have encouraged the broadest possible scope. The term 'business' is understood in a wide sense to include all systems involved in the exchange of goods and services, while 'ethics' is circumscribed as all human action aimed at securing a good life. Systems of production, consumption, marketing, advertising, social and economic 
accounting, labour relations, public relations and organisational behaviour are analysed from a moral viewpoint. The style and level of dialogue involve all who are interested in business ethics - the business community, universities, government agencies and consumer groups.

From this, it seems safe to assume that $J B E$ already attempts to attract submissions with the types of orientations advocated by Zyphur and Pierides. Whether this objective is being realized is a separate question that is arguably worth pursuing, but the appeal to incorporate ethics into $J B E$ submissions seems firmly in place.

\section{Summary and Conclusion}

Stripped to its essence, the primary message one might take away from the Zyphur and Pierides article is that quantitative researchers should pursue issues that are practically important and contextually relevant, attend to the ethical implications of their work, and choose methods that serve the substantive goals of their research. These aspirations are laudable, and perhaps they will serve as points of agreement between Zyphur and Pierides and the readers and authors of $J B E$ and other management journals. Nonetheless, I suspect many researchers will disagree that QR as it is currently practiced falls as far short of these aspirations as Zyphur and Pierides allege or that quantitative researchers are ignorant of the limitations of QR. Certainly, like any form of research, QR will always have room for improvement. However, I question whether any disconnects between $\mathrm{QR}$ and ethics are so profound that a "monumental shift in what many $\mathrm{QR}$ practitioners care about must occur" (p. 14). Rather, I believe that QR and ethics can and do peacefully coexist and that quantitative researchers should be treated as innocent until proven guilty through a comprehensive, systematic, and careful assessment of the ethics of QR. As a field, we could all benefit from this type of assessment, and I believe it would show that we are in better shape than indicated by the opinions expressed by Zyphur and Pierides. 


\section{Compliance with Ethical Standards}

Ethical approval: This article does not contain any studies with human participants or animals performed by the author.

Informed consent: Because this article does not contain any studies with human participants, informed consent is not relevant. 


\section{References}

Adams, K. A., \& Lawrence, E. K. (2019). Research methods, statistics, and applications (2nd ed.). Thousand Oaks, CA: Sage.

Aguinis, H. (1993). Action research and scientific method: Presumed discrepancies and actual similarities. Journal of Applied Behavioral Science, 29, 416-431.

Aguinis, H., Dalton, D. A., Bosco, F. A., Pierce, C. A., \& Dalton, C. M. (2011). Meta-analytic choices and judgment calls: Implications for theory building and testing, obtained effect sizes, and scholarly impact. Journal of Management, 37, 5-38.

Argyris, C., Putnam, R., \& Smith, D. M. (1985). Action science. San Francisco: Jossey-Bass.

Beauchamp, T. L., \& Bowie, N. E. (1997). Ethical theory and business. Upper Saddle River, NJ: Prentice-Hall.

Bentham, J. (1789/1961). An introduction to the principles of morals and legislation. Garden City: Doubleday.

Booth, W. C., Colomb, G. G., \& Williams, J. M. (2008). The craft of research (3rd ed.). Chicago: University of Chicago Press.

Brady, F. N. (1985). A Janus-headed model of ethical theory: Looking two ways at business/society issues. Academy of Management Review, 10, 568-576.

Brewerton, P., \& Millward, L. (2001). Organizational research methods: A guide for students and researchers. Thousand Oaks, CA: Sage.

Campbell, D. T., \& Fiske, D. W. (1959). Convergent and discriminant validation by the multitrait-multimethod matrix. Psychological Bulletin, 56, 81-105.

Connell, A. F., \& Nord, W. R. (1996). The bloodless coup: The infiltration of organization science by uncertainty and values. Journal of Applied Behavioral Science, 32, 407-427.

Cook, T. D., Campbell, D. T., \& Peracchio, L. (1990). Quasi-experimentation. In M. D. Dunnette \& L. M. Hough (Eds.), Handbook of industrial and organizational psychology (2nd ed., Vol. 1, pp. 491-576). Palo Alto, CA: Consulting Psychologists Press.

Cronbach, L. J., \& Meehl, P. C. (1955). Construct validity in psychological tests. 
Psychological Bulletin, 52, 281-302.

Cronbach, L. J., Gleser, G., Nanda, H., \& Rajaratnam, N. (1972). The dependability of behavioral measurements: Theory of generalizability for scores and profiles. New York: Wiley.

Donaldson, T. (1982). Corporations and morality. Englewood Cliffs, NJ: Prentice Hall.

Eden, D. (2017). Field experiments in organizations. Annual Review of Organizational Psychology and Organizational Behavior,

Gerber, A. S., \& Green, D. P. (2012). Field experiments: Design, analysis, and interpretation. New York: W. W. Norton \& Company.

Grant, A. M., \& Wall, T. D. (2009). The neglected science and art of quasi-experimentation: Why-to, when-to, and how-to advice for organizational researchers. Organizational Research Methods, 12, 653-686.

Greenwood, D., \& Levin, M. (Eds.). (2007). Introduction to action research: Social research for social change (2nd ed). Thousand Oaks, CA: Sage.

Harman, H. H. (1976). Modern factor analysis (3rd ed.). Chicago: University of Chicago Press.

Howard, G. S. (1985). The role of values in the science of psychology. American Psychologist, 40, $255-265$.

Hoyt, W. T. (2000). Rater bias in psychological research: When is it a problem and what can we do about it? Psychological Methods, 5, 64-86.

Kimmel, A. J. (1988). Ethics and values in applied social research. Newbury Park, CA: Sage.

Lewin, K. (1946). Action research and minority problems. Journal of Social Issues, 2, 34-46.

Mayo, E. (1933). The human problems of an industrial civilization. New York: Macmillan.

McGrath, J. E., Martin, J., \& Kulka, R. A. (Eds.). (1982). Judgment calls in research. Beverly Hills, CA: Sage.

Mill, J. S. (1861/1998). Utilitarianism (edited with an introduction by Roger Crisp). New York: Oxford University Press. 
Mowday, R. T. (1997). Reaffirming our scholarly values. Academy of Management Review, 22, $335-345$.

Mulaik, S. A. (2009). Foundations of factor analysis (2nd ed.). London: Taylor \& Francis.

Nunnally, J. C. (1978). Psychometric theory (2nd ed.). New York: McGraw-Hill.

Podsakoff, P. M., MacKenzie, S. B., \& Podsakoff, N. P. (2012). Sources of method bias in social science research and recommendations on how to control it. Annual Review of Psychology, 63, 539-569.

Reason, P., \& Bradbury, H. (Eds). (2008). The Sage handbook of action research: Participative inquiry and practice (2nd ed.). Thousand Oaks, CA: Sage.).

Rogelberg, S. G. (Ed.). (2002). Handbook of research methods in industrial and organizational psychology. Oxford: Blackwell.

Rosenthal, R., \& Rosnow, R. L. (2009). Artifacts in behavioral research. Oxford: Oxford University Press.

Shadish, W. R., Cook, T. D., \& Campbell, D. T. (2002). Experimental and quasi-experimental designs for generalized causal inference. Boston: Houghton-Mifflin.

Stringer, E. T. (2014). Action research. Los Angeles: Sage.

Tharenou, P., Donohue, R., \& Cooper, B. (2007). Management research methods. Cambridge: Cambridge University Press.

Treviño, L. K., \& Nelson, K. A. (2011). Managing business ethics (5th ed.). New York: Wiley. Velasquez, M. (2012). Business ethics: Concepts and cases (7th edition). New York: Pearson.

Wanous, J. P., Sullivan, S. E., \& Malinak, J. (1989). The role of judgment calls in metaanalysis. Journal of Applied Psychology, 74, 259-264.

Weathington, B. L., Cunningham, C. J. L., \& Pittenger, D. J. (2010). Research methods for the behavioral and social sciences. New York: Wiley.

Webb, E. J., Campbell, D. T., Schwartz, R. D., \& Sechrest, L. (1966). Unobtrusive measures: Non-reactive research in the social sciences. Skokie, IL: Rand McNally. 
Webb, E., \& Weick, K. E. (1979). Unobtrusive measures in organizational theory: A reminder. Administrative Science Quarterly, 24, 650-659.

Zyphur, M. J., \& Pierides, D. C. (2017). Is quantitative research ethical? Tools for ethically practicing, evaluating, and using quantitative research. Journal of Business Ethics, 143, $1-16$. 


\section{Table 1}

\section{Quantitative Research Studies Published in Selected Management Journals}

Academy of Management Journal, Volume 61, Issue 1, February 2018

Authors

Title

Bhave and Lefter

Desai

Eggers and Kaul

Giarratana et al.

Kim and Ployhart

Knight et al.

Lam et al.

Miron-Spektor et al.

Mueller et al.

Piazza and Jourdan
The Other Side: Occupational Interactional Requirements and

Work-Home Enrichment

Collaborative Stakeholder Engagement: An Integration Between

Theories of Organizational Legitimacy and Learning

Motivation and Ability? A Behavioral Perspective on the Pursuit

of Radical Invention in Multi-Technology Incumbents

Rewards for Patents and Inventor Behaviors in Industrial Research

and Development

The Strategic Value of Selection Practices: Antecedents and

Consequences of Firm-Level Selection Practice Usage

Organizational Affective Tone: A Meso Perspective on the Origins and Effects of Consistent Affect in Organizations

Does Proactive Personality Matter in Leadership Transitions?

Effects of Proactive Personality on New Leader Identification and

Responses to New Leaders and Their Change Agendas

Microfoundations of Organizational Paradox: The Problem is How

We Think About the Problem

Reframing the Decision-Makers' Dilemma: Towards a Social

Context Model of Creative Idea Recognition

When the Dust Settles: The Consequences of Scandals for

Organizational Competition 
Rao and Greve

Wu et al.

Yam et al.

Yu and Zellmer-Bruhn
Disasters and Community Resilience: Spanish Flu and the

Formation of Retail Cooperatives in Norway

When and Why People Engage In Different Forms of Proactive

Behavior: Interactive Effects of Self-Construals and Work

Characteristics

The Mixed Blessing of Leader Sense of Humor: Examining Costs and Benefits

Introducing Team Mindfulness and Considering its Safeguard Role Against Conflict Transformation and Social Undermining

Administrative Science Quarterly, Volume 63, Issue 1, March 2018

Authors

Title

Carlos and Lewis

Yenkey

Zhelyazkov
Strategic Silence: Withholding Certification Status as a Hypocrisy

Avoidance Tactic

Fraud and Market Participation: Social Relations as a Moderator of Organizational Misconduct

Interactions and Interests: Collaboration Outcomes, Competitive Concerns, and the Limits to Triadic Closure

Journal of Applied Psychology, Volume 103, Issue 1, January 2018

Authors

Title

Bamberger et al.

Does College Alcohol Consumption Impact Employment Upon

Graduation? Findings From a Prospective Study

Becker et al.

The Dark Side of Subjective Value in Sequential Negotiations: The Mediating Role of Pride and Anger 
Bodner et al.

Elfenbein et al.

Farh and Chen

Mitchell et al.

Wee et al.

Wolfson et al.
Detecting and Differentiating the Direction of Change and Intervention Effects in Randomized Trials

On The Relative Importance of Individual-Level Characteristics and Dyadic Interaction Effects in Negotiations: Variance Partitioning Evidence From a Twins Study Leadership and Member Voice in Action Teams: Test of a Dynamic Phase Model

Cheating Under Pressure: A Self-Protection Model of Workplace Cheating Behavior

Attention to Change: A Multilevel Theory on the Process of Emergent Continuous Organizational Change

A Cross-Level Investigation of Informal Field-Based Learning and Performance Improvements

Organizational Behavior and Human Decision Processes, Volume 144, Issue 1, January 2018 Authors Title

Cheshin et al.

The Interpersonal Effects of Emotion Intensity in Customer

Service: Perceived Appropriateness and Authenticity of

Attendants' Emotional Displays Shape Customer Trust and

Satisfaction

Gibson et al.

When Sharing Hurts: How and Why Self-Disclosing Weakness

Undermines the Task-Oriented Relationships of Higher Status

Disclosers

Houston et al.

Who Cares if "Service With a Smile" is Authentic? An

Expectancy-Based Model of Customer Race and Differential

Service Reactions 
Lee et al.

Marlow et al.

Ong et al.

Schaerer et al.

Schlosser

Sirola and Pitesa

Tang et al.

White et al.

Yip et al.

Zhang et al.
Does Gender Diversity Help Teams Constructively Manage Status

Conflict? An Evolutionary Perspective of Status Conflict, Team

Psychological Safety, and Team Creativity

Does Team Communication Represent a One-Size-Fits-All

Approach?: A Meta-Analysis of Team Communication and

Performance

When Corporate Social Responsibility Motivates Employee

Citizenship Behavior: The Sensitizing Role of Task Significance

The Illusion of Transparency in Performance Appraisals: When and Why Accuracy Motivation Explains Unintentional Feedback Inflation

What are My Chances? An Imagery Versus Discursive Processing Approach to Understanding Ratio-Bias Effects

The Macroeconomic Environment and the Psychology of Work

Evaluation

Fate as a Motivated (and De-Motivating) Belief: Evidence for a

Link From Task Importance to Belief in Fate to Effort

When Social Identity Threat Leads to the Selection of Identity-

Reinforcing Options: The Role of Public Self-Awareness

Trash-Talking: Competitive Incivility Motivates Rivalry,

Performance, and Unethical Behavior

Small Economic Losses Lower Total Compensation for Victims of Emotional Losses

Strategic Management Journal, Volume 39, Issue 1, January 2018

Authors

Title 
Arora et al.

Arts et al.

Furr and Kapoor

Jiang et al.

Li et al.

Lyons and Zhang

Oliver et al.

Vidal and Mitchell
The Decline of Science in Corporate R\&D

Text Matching to Measure Patent Similarity

Capabilities, Technologies, and Firm Exit During Industry

Shakeout: Evidence from the Global Solar Photovoltaic Industry

Do Ongoing Networks Block Out New Friends? Reconciling the

Embeddedness Constraint Dilemma on New Alliance Partner

Addition

On the Duality of Political and Economic Stakeholder Influence on

Firm Innovation Performance: Theory and Evidence from Chinese

Firms

Who Does (Not) Benefit From Entrepreneurship Programs?

BS in the Boardroom: Benevolent Sexism and Board Chair

Orientations

Virtuous or Vicious Cycles? The Role of Divestitures as a

Complementary Penrose Effect Within Resource-Based Theory 